\title{
The Route of Estrogen Replacement Therapy Confers Divergent Effects on Substrate Oxidation and Body Composition in Postmenopausal Women
}

\author{
Anthony J. O’Sullivan, ${ }^{\star}$ Leonie J. Crampton, ${ }^{\star}$ Judith Freund, ${ }^{\ddagger}$ and Ken K.Y. Ho* \\ *Garvan Institute of Medical Research, and ${ }^{\ddagger}$ Department of Nuclear Medicine, St. Vincent’s Hospital, Sydney NSW 2010, Australia
}

\section{Abstract}

The route of estrogen replacement therapy has a major impact on the growth hormone (GH)/insulin-like growth factor-I (IGF-I) axis. Estrogen administration by the oral, but not the transdermal route, reduces IGF-I and increases GH levels in postmenopausal women. To investigate whether these perturbations have metabolic consequences, we compared the effects of $24 \mathrm{wk}$ each of oral (Premarin $1.25 \mathrm{mg}$ ) and transdermal (Estraderm 100TTS) estrogen on energy metabolism and body composition in 18 postmenopausal women in an open-label randomized crossover study. Energy expenditure, lipid oxidation $\left(\right.$ lipid $\left._{\text {ox }}\right)$, and carbohydrate oxidation $\left(\mathrm{CHO}_{\text {ox }}\right)$ were measured by indirect calorimetry in the fasted and fed state before and after 2 and 6 mon treatment. Lean body mass, fat mass, and total body bone mineral density were measured by dual X-ray absorptiometry before and after 6 mon treatment.

Mean ( \pm SE) Luteinizing hormone levels fell to comparable levels during oral and transdermal estrogen, and bone mineral density was significantly increased by both treatments. Mean IGF-I was significantly lower during oral estrogen $(77 \pm 7$ versus $97 \pm 7 \mu \mathrm{g} / \mathrm{liter}, P<0.05)$ treatment. Lipid $_{\text {ox }}$ 30-60 min after a standardized meal was significantly lower $(36 \pm 5$ versus $54 \pm 5 \mathrm{mg} / \mathrm{min}, P<0.01)$ and $\mathrm{CHO}_{\text {ox }}$ higher $(147 \pm 13$ versus $109 \pm 12 \mathrm{mg} / \mathrm{min}, P<0.05)$ with oral compared with transdermal estrogen. Oral estrogen resulted in a $1.2 \pm 0.5 \mathrm{~kg}(P<0.05)$ increase in fat mass and a $1.2 \pm 0.4 \mathrm{~kg}(P<0.01)$ decrease in lean mass compared with transdermal estrogen. Lean body mass $(0.4 \pm 0.2$ $\mathrm{kg})$ and fat mass $(0.1 \pm 0.4 \mathrm{~kg})$ did not change significantly during transdermal estrogen.

In summary, when compared with the transdermal route, oral estrogen reduces lipid ${ }_{\mathrm{ox}}$, increases fat mass, and reduces lean body mass. The route of estrogen therapy confers distinct and divergent effects on substrate oxidation and body composition. The suppression of lipid ${ }_{\mathrm{ox}}$ during oral estrogen therapy may increase fat mass although the fall in IGF-I may lead to a loss of lean body mass. The route-dependent changes in body composition observed during estrogen replacement therapy may have important implications for

Address correspondence to Ken K.Y. Ho, Garvan Institute of Medical Research, St. Vincent's Hospital, 384 Victoria Street, Sydney NSW 2010, Australia. Phone: 61-2-295-8200; FAX: 61-2-295-8201; E-mail: k.ho@garvan.unsw.edu.au

Received for publication 8 January 1998 and accepted in revised form 17 June 1998.

J. Clin. Invest.

(C) The American Society for Clinical Investigation, Inc. 0021-9738/98/09/1035/06 \$2.00

Volume 102, Number 5, September 1998, 1035-1040

http://www.jci.org postmenopausal health. (J. Clin. Invest. 1998. 102:10351040.) Key words: growth hormone - insulin-like growth factor-I • estrogen • body composition • metabolism

\section{Introduction}

The route of estrogen replacement therapy in postmenopausal women has a major impact on the growth hormone $(\mathrm{GH})^{1} /$ insulin-like growth factor-I (IGF-I) axis $(1,2)$. Estrogen administered via the oral but not the transdermal route reduces serum IGF-I and increases circulating GH as well as GH-binding protein levels. $\mathrm{GH}$ has major effects on substrate metabolism and body composition $(3,4,5,6,7)$. The anabolic actions of $\mathrm{GH}$ are mediated through IGF-I, whereas other metabolic actions such as stimulation of lipolysis and lipid oxidation are direct. GH circulates partly bound to a high affinity binding protein, GH-binding protein, that alters the pharmacokinetics and distribution of GH (8) and may modulate GH action (9).

Because three major components of the somatotropic axis (GH, IGF-I, and GH-binding protein) are markedly affected by oral but not transdermal estrogen administration, we postulated that estrogen may exert significant metabolic effects that are dependent on its route of administration. To this end, we have undertaken a study to compare the effects of oral and transdermal estrogen administration on substrate oxidation and body composition in postmenopausal women.

\section{Methods}

Subjects. 23 healthy postmenopausal women were recruited from the general population. All subjects had cessation of menses for at least 12 mon with postmenopausal status confirmed by elevated gonadotrophins and low estradiol levels. 18 subjects completed the study (mean \pm SE) $; 57 \pm 1 \mathrm{yr}$, height $161.5 \pm 1.4 \mathrm{~cm}$, weight $69.5 \pm 2.1 \mathrm{~kg}$, body mass index $26.8 \pm 1.0 \mathrm{~kg} / \mathrm{m}^{2}$ ). Four subjects withdrew before completion; two because of irregular menstrual bleeding, one from a local allergic skin reaction to the transdermal medication, and one from an adverse experience unrelated to the trial medication. One subject commenced competitive sport that constituted a violation of the trial protocol. All subjects were in good health and were on no other medications. 10 subjects had not previously received estrogen replacement therapy. Eight subjects ceased estrogen replacement therapy at least 2 mon before entry into the study. The study was approved by the Research Ethics Committee of St. Vincent's Hospital. All subjects gave informed consent.

Study design. The design was an open-label randomized crossover study that allowed for the difference in treatment effect to be compared. Each subject was randomized to oral-conjugated estrogen $1.25 \mathrm{mg}$ (Premarin, Wyeth-Ayerst, Philadelphia, PA) daily or transdermal estrogen patches (Estraderm-TTS 100, Ciba-Geigy, Sydney, Australia) delivering $100 \mu \mathrm{g}$ of $17 \beta$-estradiol daily for $24 \mathrm{wk}$ and the

1. Abbreviations used in this paper: $\mathrm{BMD}$, bone mineral density; $\mathrm{CV}$, coefficient of variation; $\mathrm{FSH}$, follicle-stimulating hormone; $\mathrm{GH}$, growth hormone; IGF-I, insulin-like growth factor-I; LH, luteinizing hormone. 
patches were changed twice per week. The subjects then crossed over to the alternate estrogen treatment for a further $24 \mathrm{wk}$. 8 subjects were randomized to oral, and 10 to transdermal therapy at initiation. The dosage of each estrogen type was selected on the basis of published data indicating equivalent biological activity based on gonadotrophin suppression and changes in vaginal cytology $(10,11,12)$. Medroxy progesterone acetate $10 \mathrm{mg}$ daily was coadministered on the last $12 \mathrm{~d}$ of each 4 -wk cycle for the $48 \mathrm{wk}$ ( 12 cycles) of total estrogen exposure. All investigations were performed in the estrogen only phase. Medications were administered as an 8-wk batch and compliance was checked by pill and patch counting. Subjects were instructed to follow their usual diet and exercise pattern.

Body composition was measured before and at the end of each estrogen treatment phase. Indirect calorimetry was performed before treatment and at 8 and $24 \mathrm{wk}$ of each estrogen treatment phase. Fasting serum GH, IGF-I, follicle-stimulating hormone (FSH), luteinizing hormone $(\mathrm{LH})$, thyroid-stimulating hormone, free tri-iodothyronine (free T3), free thyroxine (free T4), glucose, insulin, cholesterol, and triglyceride levels were measured before entry and at 24 and $48 \mathrm{wk}$.

Study techniques. Energy expenditure and substrate oxidation were measured by indirect calorimetry during the fasting and postprandial states, using the Deltatrac Metabolic Monitor (Datex Instrumentarium Corp., Helsinki, Finland), as previously described (13). Subjects presented at 8 a.m. after an overnight 12 -h fast. A small plastic intravenous cannula was inserted under local anaesthetic for blood withdrawal. Subjects were then rested comfortably in the recumbent position for at least $40 \mathrm{~min}$ in preparation for measurement of basal energy expenditure and substrate oxidation, which was performed over the next $30 \mathrm{~min}$. A standardized mixed meal (14.0\% protein, $31.5 \%$ fat, $54.5 \%$ carbohydrate; Ensure, Ross Laboratories, Columbus, $\mathrm{OH}$ ) was then administered over $5 \mathrm{~min}$, and indirect calorimetry was performed during the 30-60-, 90-120-, and 150-180-min time intervals after the nutrient load. The mixed meal consisted of the caloric equivalent of $40.0 \%$ of the subject's basal energy expenditure measured at the first study. For each subject, the identical meal quantity was used in subsequent studies. Separate urine samples were collected during the basal and meal periods from which urine urea nitrogen excretion was measured. Energy expenditure and substrate oxidation were estimated from the following equations (14): energy expenditure $=3.91 \mathrm{VO}_{2}+1.10 \mathrm{VCO}_{2}-3.34 \mathrm{~N}_{\mathrm{u}}$; carbohydrate oxidation $=$ $4.55 \mathrm{VCO}_{2}-3.21 \mathrm{VO}_{2}-2.87 \mathrm{~N}_{\mathrm{u}}$; lipid oxidation $=1.67 \mathrm{VO}_{2}-1.67$ $\mathrm{VCO}_{2}-1.92 \mathrm{~N}_{\mathrm{u}}$. Carbohydrate and lipid oxidation are expressed as grams per min. $\mathrm{VO}_{2}$ represents oxygen consumption and $\mathrm{VCO}_{2}$ represents carbon dioxide production in liters per min. $\mathrm{N}_{\mathrm{u}}$ represents urinary urea nitrogen excretion in grams per min. The monitor was calibrated against standardized gases before each study. The coefficient of variation $(\mathrm{CV})$ from five subjects studied on three separate occasions for energy expenditure was $4.2 \%$, and substrate oxidation was $4 \%$.

Body composition was measured by dual X-ray absorptiometry (Lunar DPX, Lunar Radiation Corp., Madison, WI) $(6,7)$. Dual X-ray absorptiometry provides a three-compartment model allowing total body bone mineral density (BMD), fat, and lean body mass to be quantified for the whole body and the three standard regions of trunk, arms, and legs. Central soft tissue composition was determined by defining a window extending from the top of the second to the bottom of the fourth lumbar vertebrae. In our laboratory the CV from 10 subjects scanned four times was $1.5 \%$ for BMD, $2.9 \%$ for fat mass, and $1.4 \%$ for lean body mass. The body composition data are expressed as the absolute changes in BMD, fat, and lean body mass observed during each of the estrogen treatment phases.

Laboratory analysis. GH and insulin were measured by double antibody radioimmunoassay as previously described (15). IGF-I was measured by radioimmunoassay after acid ethanol extraction using a recombinant human IGF-I standard (16). LH, FSH, thyroid-stimulating hormone, free $\mathrm{T} 3$, and free $\mathrm{T} 4$ were measured by immunoassays as previously described $(1,6)$. Glucose concentrations were analyzed on a glucose analyzer (Model 23AM, Yellow Springs Instrument Co.,
Yellow Springs, OH). Serum cholesterol and triglyceride levels were measured with an automated enzymatic method. Urinary urea nitrogen was measured by an enzymatic ultraviolet method (Boehringer Mannheim, Mannheim, Germany) and the inter- and intra-assay CV were 13 and $6 \%(6)$.

Statistical analysis. Statistical analysis was performed with the aid of the SAS statistical package (SAS/Stat, SAS Institute 1990, Cary, NC) using a random ANOVA model. GH levels were log transformed to achieve normal distribution before data analysis. Analysis for interactions between treatment and sequence was performed using the Grizzle Method (17). Treatment effects on substrate oxidation were analyzed by ANOVA with repeated measures with the degree of significance determined by Dunnet's test. Results are expressed as \pm SEM.

\section{Results}

Endocrine data (Table I). Both routes of estrogen therapy significantly reduced mean $\mathrm{LH}$ and FSH levels to the same degree after $24 \mathrm{wk}$. The mean fasting $\mathrm{GH}$ level at this time was significantly higher during oral estrogen than during transdermal estrogen therapy, and also higher than before starting treatment. Mean IGF-I level was significantly reduced by oral but not by transdermal estrogen therapy. Thyroid function tests were normal in all subjects before treatment and did not change significantly during either estrogen treatment. Mean fasting glucose or insulin levels were not significantly different between oral or transdermal estrogen therapies nor were the levels different from those obtained before treatment. The mean fasting triglyceride level obtained during oral estrogen treatment was significantly higher than that observed during transdermal therapy. The mean fasting cholesterol level was not significantly altered by oral or transdermal estrogen therapy.

Energy metabolism. Indirect calorimetry was performed before treatment and at 8 and 24 wk into each estrogen treatment phase. No significant difference in basal energy expenditure and diet-induced thermogenesis was observed between oral or transdermal estrogen therapy at 8 or $24 \mathrm{wk}$, nor did these measures of energy expenditure differ from those obtained before treatment (Fig. 1).

Table I. Clinical and Fasting Biochemical Characteristics at Pretreatment and After 24 wk of Oral and Transdermal Estrogen Therapy in the 18 Postmenopausal Women

\begin{tabular}{lccc}
\hline & Pretreatment & Oral & Transdermal \\
\hline Body weight (kg) & $69.5 \pm 2.1$ & $70.3 \pm 2.0$ & $70.2 \pm 1.9$ \\
LH (IU/liter) & $30.9 \pm 2.7$ & $10.7 \pm 2.5^{\S}$ & $12.9 \pm 1.9^{\S}$ \\
FSH (IU/liter) & $62.9 \pm 5.2$ & $16.4 \pm 2.6^{\S}$ & $24.7 \pm 2.1^{\S}$ \\
GH ( $\mu$ g/liter) & $0.4 \pm 0.1$ & $1.4 \pm 0.2^{\S \pi}$ & $0.5 \pm 0.2$ \\
IGF-I ( $\mu$ g/liter) & $108 \pm 10$ & $77 \pm 7^{\S \pi}$ & $97 \pm 7$ \\
TSH (mU/liter) & $1.6 \pm 0.2$ & $1.6 \pm 0.2$ & $1.7 \pm 0.2$ \\
Free T3 (pmol/liter) & $7.2 \pm 0.2$ & $6.7 \pm 0.2$ & $6.8 \pm 0.2$ \\
Free T4 (pmol/liter) & $14.7 \pm 0.5$ & $15.4 \pm 0.4$ & $14.6 \pm 0.4$ \\
Glucose (mmol/liter) & $4.6 \pm 0.1$ & $4.7 \pm 0.1$ & $4.9 \pm 0.1$ \\
Insulin (pmol/liter) & $45 \pm 5$ & $40 \pm 5$ & $45 \pm 5$ \\
Triglycerides (mmol/liter) & $1.0 \pm 0.1$ & $1.4 \pm 0.2^{\llbracket}$ & $0.8 \pm 0.1$ \\
Cholesterol (mmol/liter) & $4.8 \pm 0.3$ & $4.9 \pm 0.2$ & $5.2 \pm 0.2$
\end{tabular}

Results expressed as mean \pm SE. ${ }^{~} P<0.05$ oral versus transdermal, ${ }^{\S} P<$ 0.05 versus pretreatment. 
A
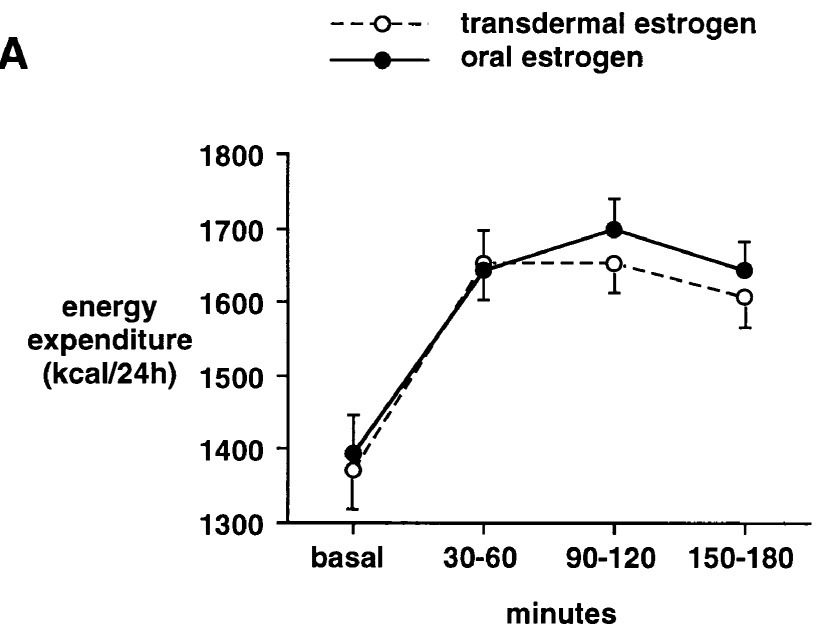

B
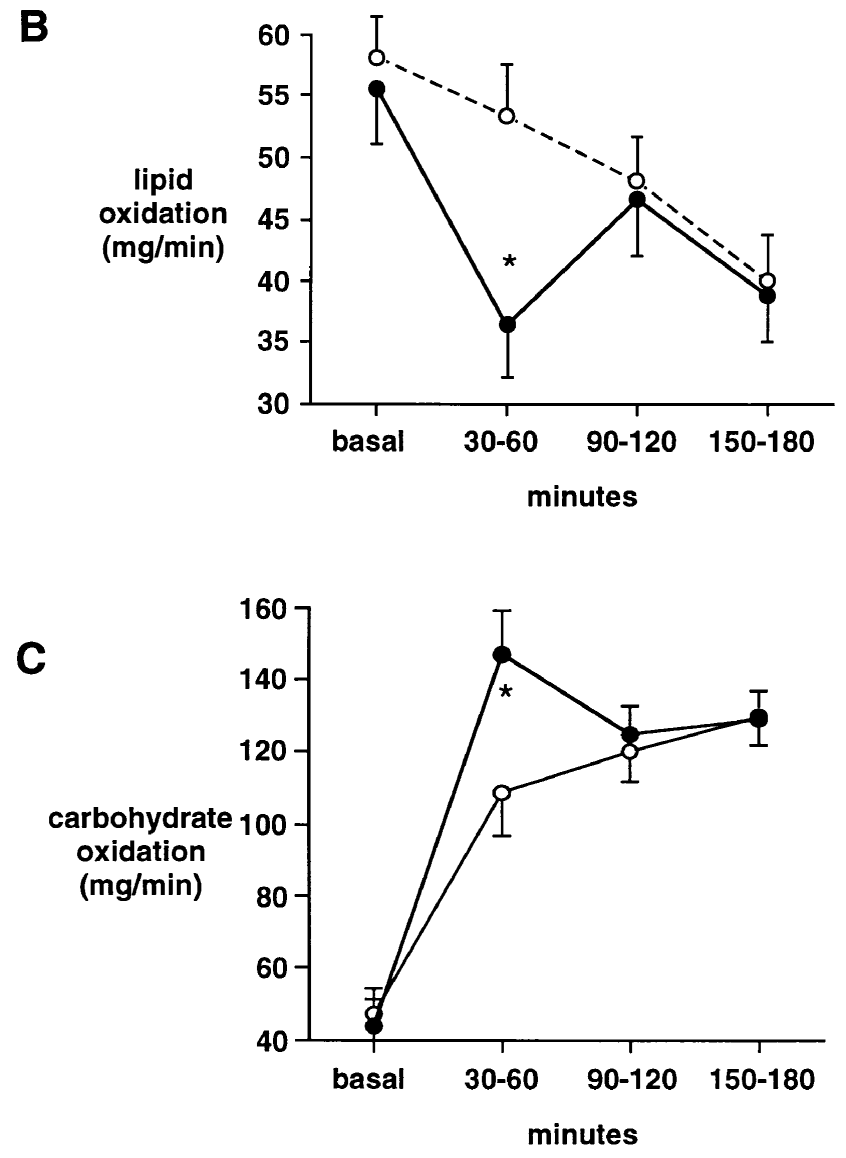

Figure 1. Mean \pm SE Energy expenditure $(A)$, lipid $(B)$, and carbohydrate oxidation $(C)$ after $8 \mathrm{wk}$ of oral and transdermal estrogen therapy. $* P<0.01$.

No significant difference in basal lipid oxidation was observed between the two routes of estrogen therapy after $8 \mathrm{wk}$ (Fig. 1; Table II). Ingestion of the mixed meal acutely suppressed lipid oxidation during each treatment phase. However, when compared with the transdermal route, oral estrogen administration resulted in a greater suppression of lipid oxidation during the first hour after ingestion of the standardized meal (Fig. 1). This greater but transient suppression of lipid oxida-
Table II. Lipid (top) and Carbohydrate (CHO) Oxidation (bottom) in the Basal State and After the Mixed Meal at Pretreatment and After 8 and 24 wk of Oral and Transdermal Estrogen Therapy in the 18 Postmenopausal Women

\begin{tabular}{llllllc}
\hline & & \multicolumn{2}{c}{ Oral } & & \multicolumn{2}{c}{ Transdermal } \\
\cline { 3 - 4 } \cline { 7 - 8 } $\begin{array}{c}\text { Lipid oxidation } \\
(\mathrm{Mg} / \mathrm{min})\end{array}$ & Pretreatment & $8 \mathrm{wk}$ & $24 \mathrm{wk}$ & & $8 \mathrm{wk}$ & $24 \mathrm{wk}$ \\
\hline Basal & $56.7 \pm 3.6$ & $55.5 \pm 4.8$ & $52.1 \pm 3.8$ & & $58.0 \pm 4.2$ & $55.0 \pm 3.3$ \\
$30-60 \mathrm{~min}$ & $45.2 \pm 6.2$ & $36.4 \pm 4.7^{*}$ & $33.9 \pm 3.6^{\dagger}$ & & $53.9 \pm 4.9$ & $43.4 \pm 5.7$ \\
$90-120 \mathrm{~min}$ & $45.2 \pm 4.8$ & $47.1 \pm 4.5$ & $46.4 \pm 4.2$ & & $48.1 \pm 3.8$ & $45.1 \pm 3.9$ \\
$150-180 \mathrm{~min}$ & $37.0 \pm 4.9$ & $39.3 \pm 4.0$ & $45.0 \pm 3.8$ & & $40.5 \pm 3.3$ & $35.5 \pm 3.4$
\end{tabular}

\begin{tabular}{lcccccc}
\hline & & \multicolumn{2}{c}{ Oral } & & \multicolumn{2}{c}{ Transdermal } \\
\cline { 3 - 4 } $\begin{array}{c}\text { CHO oxidation } \\
(\mathrm{Mg} / \mathrm{min})\end{array}$ & Pretreatment & $8 \mathrm{wk}$ & $24 \mathrm{wk}$ & & $8 \mathrm{wk}$ & $24 \mathrm{wk}$ \\
\hline Basal & $49 \pm 7$ & $44 \pm 10$ & $44 \pm 10$ & & $47 \pm 7$ & $37 \pm 8$ \\
$30-60 \mathrm{~min}$ & $127 \pm 13$ & $147 \pm 13^{\ddagger}$ & $149 \pm 10^{\S}$ & & $109 \pm 12$ & $115 \pm 11$ \\
$90-120 \mathrm{~min}$ & $130 \pm 10$ & $125 \pm 8$ & $134 \pm 9$ & & $120 \pm 8$ & $119 \pm 9$ \\
$150-180 \mathrm{~min}$ & $134 \pm 10$ & $129 \pm 9$ & $123 \pm 7$ & & $130 \pm 7$ & $129 \pm 7$
\end{tabular}

Results expressed as mean $\pm \mathrm{SE}$ in $\mathrm{mg} / \mathrm{min} .{ }^{*} P=0.003$ oral versus transdermal, ${ }^{\dagger} P=0.009$ oral versus transdermal, ${ }^{\ddagger} P=0.002$ oral versus transdermal, ${ }^{\S} P=0.02$ oral versus transdermal.

tion in the early postprandial phase induced by the oral route was present at $24 \mathrm{wk}$ of treatment (Table II).

No significant difference in basal carbohydrate oxidation between the two routes of estrogen therapy was observed after 8 wk (Fig. 1). Ingestion of the mixed meal increased carbohydrate oxidation during each treatment phase. However, when compared with the transdermal route, oral estrogen administration resulted in a greater increase in carbohydrate oxidation during the first hour after ingestion of the standardized meal (Fig. 1). A greater but transient increase in carbohydrate oxidation in the early postprandial phase was also present with the oral route at $24 \mathrm{wk}$ (Table II). No significant changes in urinary urea nitrogen excretion were observed in the basal state or during the mixed meal during either estrogen treatment (data not shown). Thus, when compared with transdermal estrogen, oral estrogen therapy resulted in an early but transient suppression of lipid oxidation and a reciprocal elevation of carbohydrate oxidation after a nutrient load.

Body composition. The data were analyzed to determine whether significant changes in body weight, BMD, fat mass, and lean body mass occurred between the two routes of estrogen therapy. No significant changes in body weight were observed between both routes of estrogen therapy after $24 \mathrm{wk}$, nor did body weight change significantly with either treatment (Fig. 2). Mean BMD increased during oral $(\triangle \mathrm{BMD}=$ $\left.0.008 \pm 0.004 \mathrm{gm} / \mathrm{cm}^{2}, P=0.06\right)$ and during transdermal estrogen therapy $\left(\Delta \mathrm{BMD}=0.022 \pm 0.010 \mathrm{gm} / \mathrm{cm}^{2}, P<0.05\right)$, with the increases not being significantly different between the two routes.

Significantly different effects on fat mass and lean body mass were observed between the two routes of estrogen therapy. When the effects of both routes of estrogen administration were compared, oral therapy led to a significant increase in fat mass of $1.2 \pm 0.5 \mathrm{~kg}(P<0.05$, Fig. 2) equivalent to $4.9 \pm 1.6 \%$ (Table III) change in body fat. This increase in fat mass arose from a significant increase occurring during $24 \mathrm{wk}$ 
A

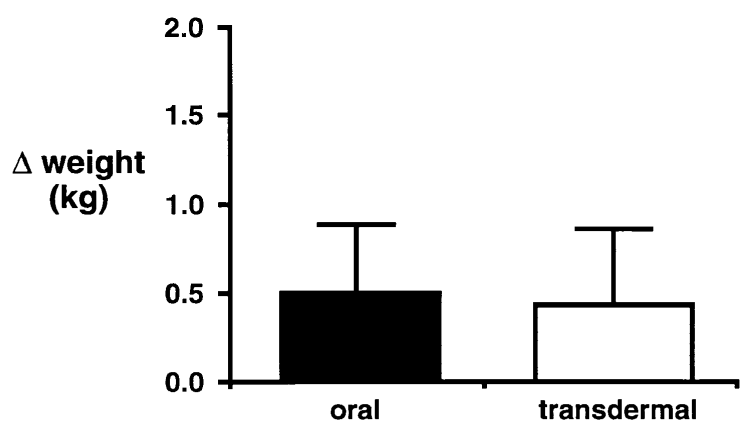

B

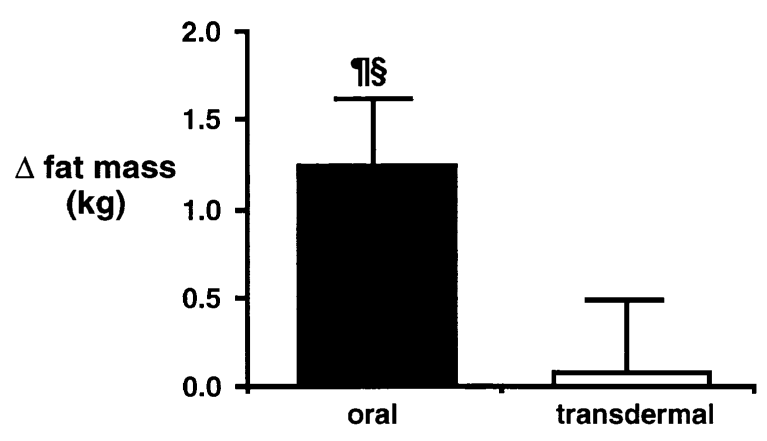

C

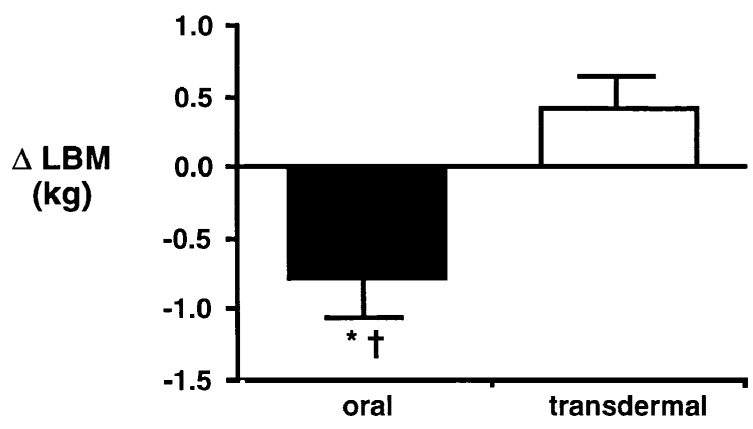

Figure 2. Change $( \pm$ SEM) in body weight $(A)$, fat mass $(B)$, and lean body mass $(L B M, C)$ after $24 \mathrm{wk}$ of oral and transdermal estrogen treatment. $P<0.05$ oral versus transdermal, ${ }^{*} P<0.01$ oral versus transdermal, ${ }^{\ddagger} P<0.02$ versus before oral estrogen treatment, ${ }^{\circledR} P<$ 0.005 versus before oral estrogen treatment.

of oral therapy with no significant change occurring during the transdermal estrogen phase (Table III). Analysis of regional changes revealed that central fat mass increased by $3.1 \%$ (median) during oral estrogen therapy when compared with a $1.0 \%$ (median) decrease occurring during the transdermal phase, although the difference did not reach statistical significance $(P=0.08$, Mann-Whitney test). The change in peripheral fat mass was not significant between treatments. Oral estrogen therapy resulted in a significant loss in lean body mass of $1.2 \pm 0.4 \mathrm{~kg}(P<0.05$, equivalent to a $3.1 \pm 0.8 \%$ change $)$ compared with that observed during transdermal estrogen therapy. This difference was accounted for by a significant decrease in lean body mass of $0.8 \pm 0.3 \mathrm{~kg}$ with oral therapy and a small but nonsignificant increase in lean body mass with transdermal estrogen therapy (Table III). Thus, when compared with the transdermal route, oral estrogen therapy was accom-
Table III. Change ( $\Delta)$ in Body Weight, Lean Body Mass, Fat Mass, and Percent Lean Body Mass and Fat Mass After 24 wk of Oral and Transdermal Estrogen Therapy in the 18 Postmenopausal Women

\begin{tabular}{lcc}
\hline & Oral & Transdermal \\
\hline$\Delta$ Body weight (kg) & $0.5 \pm 0.4$ & $0.4 \pm 0.5$ \\
$\Delta$ Lean body mass $(\mathrm{kg})$ & $-0.8 \pm 0.3^{* \dagger}$ & $0.4 \pm 0.2$ \\
$\Delta$ Fat mass $(\mathrm{kg})$ & $1.2 \pm 0.4^{\text {ฯा }}$ & $0.1 \pm 0.5$ \\
Percent change in lean body mass & $-2.0 \pm 0.8^{* \S}$ & $1.1 \pm 0.6$ \\
Percent change in fat mass $(\%)$ & $5.2 \pm 1.6^{* \S}$ & $0.3 \pm 1.8$
\end{tabular}

Results expressed as mean \pm SE. ${ }^{\pi} P<0.05$ oral versus transdermal, $* P<$ 0.01 oral versus transdermal, ${ }^{\dagger} P<0.02$ versus beginning of oral estrogen treatment, ${ }^{\S} P<0.005$ versus beginning of oral estrogen treatment.

panied by a significant decrease in lean body mass and a significant increase in whole body fat mass.

\section{Discussion}

This randomized crossover study shows that estrogen has metabolic effects that are dependent on the route of administration. We confirm previous observations that oral but not transdermal estrogen administration increases $\mathrm{GH}$ and decreases IGF-I levels $(1,2)$. When compared with the transdermal route, oral estrogen therapy resulted in an acute but greater transient suppression of postprandial lipid oxidation and a reciprocal increase in carbohydrate oxidation. Estrogen therapy irrespective of the route of administration did not alter energy expenditure. Whereas oral and transdermal estrogen therapy both increased BMD, the route of administration had different effects on soft tissue body composition. When compared with the transdermal route, oral estrogen therapy led to a significant decrease in lean body mass and a significant increase in fat mass with a trend towards central deposition. These changes in body composition occurred without any change in body weight. Although estrogen treatment has little impact on body weight in postmenopausal women $(18,19)$, a shift in body composition from denser lean to lighter fat tissue will be accompanied by an increase in body volume. This effect may explain the frequent self perception of increased adiposity in oral estrogen users $(20,21)$.

Although both routes of estrogen administration increased BMD, they had different effects on soft tissue body composition. The mechanism(s) responsible for the changes in body composition is not known but may arise from long term biological consequences of the suppression of lipid oxidation and IGF-I levels by oral but not transdermal estrogen administration. We speculate that the increase in body fat observed during oral estrogen therapy arises from chronic suppression of lipid oxidation. A similar mechanism has been proposed for the increased adiposity associated with moderate ethanol intake (22). Reduced lipid oxidation has also been reported to be a predictor of adiposity (23). We also propose that the loss of lean body mass observed during oral estrogen administration arises from chronic suppression of IGF-I levels in the light of strong evidence that circulating IGF-I has potent anabolic actions. IGF-I administration has been shown to promote nitrogen retention (24), stimulate body protein synthesis (25), 
reduce protein oxidation (26), and to prevent protein catabolism in humans (25). Moreover, lean body mass is decreased in GH deficiency where IGF-I is low (7), and increased in acromegaly where IGF-I is elevated (6). No functional assessment was performed in our study and future work will need to assess whether the changes in lean body mass affects physical fitness and strength.

We determined whether the transient suppression of lipid oxidation, occurring during the postprandial period, could account for the increase in fat mass observed over 6 mon of treatment. On average with oral estrogen treatment, fat oxidation is reduced by about $900 \mathrm{mg}$ after a mixed meal, and if extrapolated to three meals a day, equates to a reduction of fat oxidation of $2.7 \mathrm{~g} /$ day. Over a 6 mon period, this represents a cumulative gain of $\sim 500 \mathrm{~g}$ of fat. Given that the mean gain in fat mass was $1200 \mathrm{~g}$ over the 6 mon of oral estrogen treatment, it may be assumed that the net difference ( $700 \mathrm{~g}$ ) represents the cumulative difference occurring at other times during the day ( $21 \mathrm{~h}$ each day), but which may be below the sensitivity of detection. This equates to an average difference in fat oxidation of $\sim 3.05 \mathrm{mg}$ per min between the two treatments. Indeed, examination of our data show basal (preprandial) lipid oxidation to be slightly lower during oral therapy (Fig. $1 B$ ) with the difference being respectively $2.5 \mathrm{mg}$ per min at 2 mon and 2.9 $\mathrm{mg}$ per min at 6 mon. Although the difference did not reach statistical significance, it is a close approximation of theoretical predictions and strongly supports the hypothesis that the suppression of lipid oxidation, though mild, can account for the gain in fat mass over 6 mon of treatment.

The present study extends the observations made in a young girl treated with high doses of ethinyl estradiol (27). In this case report, we observed that oral ethinyl estradiol treatment with doses of 60,100 , and $200 \mu \mathrm{g} / \mathrm{d}$ produced a reversible, dose-dependent suppression of lipid oxidation associated with a reversible increase in fat mass. Lipid oxidation was reduced throughout the basal and postprandial states during ethinyl estradiol treatment, in contrast to significant suppression occurring only during the postprandial phase in the present study. As the potency of ethinyl estradiol in the doses used is considerably higher than that of conjugated estrogen, the observations suggests that the inhibitory effect of oral estrogen on lipid oxidation is dose dependent.

We have previously observed consistently that oral but not transdermal estrogen increases $\mathrm{GH}$ secretion and postulated that this occurs as a result of reduced feedback inhibition by IGF-I $(1,2,12)$. Interestingly, effects of increased GH secretion on lipid oxidation were not observed. On the contrary, the opposite occurred, suggesting that concomitant increases in GH-binding protein that is increased by oral but not transdermal estrogen administration, reduced $\mathrm{GH}$ action (1). GHbinding protein has been shown in vitro to attenuate $\mathrm{GH}$ action (9). Because GH stimulates lipolysis and lipid oxidation $(5,28)$, the suppression in lipid oxidation may have occurred secondarily to an oral estrogen-induced increase in circulating GH-binding protein, which was sufficient to overcome the parallel increase in GH levels. The associated fall in IGF-I with oral estrogen provides further evidence that $\mathrm{GH}$ action was attenuated at the hepatic level.

An alternate mechanism may involve a direct inhibitory effect of estrogen on the liver, a major site of fatty acid metabolism. This proposal is supported by in vitro studies showing that pharmacological concentrations of estrogen reduce keto- genesis (a product of fatty acid oxidation) and increase fatty acid incorporation into triglycerides $(29,30)$. These in vitro findings are in accordance with clinical observations that oral but not transdermal estrogen therapy stimulates hepatic triglyceride synthesis and increases triglyceride levels (31). Because intrahepatic fatty acid metabolism is partitioned between oxidative and nonoxidative (fatty acid incorporation into triglycerides) pathways, these findings suggest that estrogen may regulate the metabolic fate of intrahepatic free fatty acids by directing fatty acids away from oxidative into lipogenic pathways. This proposal is supported by the finding of a strong inverse relationship between lipid oxidation and triglyceride levels during treatment with various estrogen doses (27) and the present observations of increased triglyceride levels during oral, but not transdermal estrogen therapy, when lipid oxidation was inhibited.

Although dissimilar estrogen formulations were used for the oral and transdermal routes, it is unlikely that the contrasting biological effects arose from chemical differences. We have previously shown that different estrogen formulations cause an equal dissociation of the GH/IGF-I axis when administered via the oral route (2). The extent of IGF-I suppression was related to the degree of gonadotrophin suppression and the extent of elevation of estrogen-sensitive hepatic proteins such as GHbinding protein, sex hormone-binding globulin, and angiotensinogen. This observation suggests that IGF-I suppression is a consequence of a first pass hepatic effect arising from exposure to supra physiological concentrations of estrogens (1, 2). Along with our earlier observations that a different oral estrogen formulation suppressed lipid oxidation (27) and IGF-I levels (1), the reduction in lipid oxidation detected in the present study is also likely to be a first pass hepatic effect of orally administered estrogen.

The body compositional consequences of oral estrogen therapy are similar to those of aging, which is accompanied by a progressive increase in fat mass and a decline in lean body mass (32). An increase in fat mass of $5 \%$ and a fall in lean body mass of $2 \%$ occurred during oral estrogen treatment. These changes appear to be of biological significance when compared with the spontaneous increase in fat mass of $5-10 \%$ per decade $(1.5-2.5 \mathrm{~kg})$ and decrease in lean body mass of $2.5 \%(1-1.5 \mathrm{~kg})$ per decade observed in normal adult women with aging (32, $33,34,35)$. When compared with the transdermal route, oral estrogen administration of $1.25 \mathrm{mg}$ of conjugated estrogen for only 6 mon induced changes in body composition equivalent to those occurring spontaneously over a $5-10$-yr period. The oral dose of estrogen used for menopausal replacement therapy is generally lower than that used in the present study with a recent study reporting that $80 \%$ of estrogen users are taking a lower dose (36). Although it is likely that smaller changes will occur with lower oral doses, the changes in fat and lean body mass induced by oral estrogen raise the concern that the traditional mode of estrogen administration may compound the undesirable changes in body composition that are already occurring with aging. Evidence that the change in fat mass induced by oral estrogen use may be metabolically significant is suggested by our recent observation from a 3 mon crossover study of a trend towards reduced glucose tolerance and insulin action during oral treatment compared with transdermal treatment (12).

The increase in fat mass induced by oral estrogen treatment in the present study stands in contrast to reports that women on hormone replacement therapy have lower body 
mass indices than nonusers $(37,38,39,40)$. One possible explanation may be the selection bias inherent in nonprospective, nonrandomized design of these studies (41), in view of evidence that estrogen users are quite different from nonusers with regards to health promotion, disease prevention measures, and exercise regimens than nonusers $(42,43,44)$. Prospective studies are required to determine the extent these changes in body composition impact on fitness and health in the doses used for postmenopausal therapy.

In summary, the present study shows that the route of estrogen administration has distinct and divergent effects on substrate oxidation and body composition in postmenopausal women. This phenomenon occurs as a consequence of a first pass effect of estrogen on the metabolic and endocrine functions of the liver. Undesirable changes in body composition can be avoided in postmenopausal estrogen users by a nonoral route of administration. The findings of route-dependent changes in body composition add a new dimension to health considerations concerning estrogen therapy in postmenopausal women and estrogen use in general.

\section{Acknowledgments}

This work was supported in part by Ciba-Geigy Australia and the National Health and Medical Research Council of Australia.

\section{References}

1. Weissberger, A.J., K.K.Y. Ho, and L. Lazarus. 1991. Contrasting effects of oral and transdermal routes of estrogen replacement therapy on 24-hour growth hormone $(\mathrm{GH})$ secretion, insulin-like growth factor I and GH-binding protein in postmenopausal women. J. Clin. Endocrinol. Metab. 72:374-381.

2. Kelly, J.J., I.A. Rajkovic, A.J. O'Sullivan, C. Sernia, and K.K.Y. Ho. 1993. Effects of different oral oestrogen formulations on insulin-like growth factor-I, growth hormone and growth hormone binding protein in post-menopausal women. Clin. Endocrinol. (Oxf.). 39:561-567.

3. Jorgensen, J.O.L., L. Theusen, T. Ingemann-Hansen, S.A. Pedersen, J. Jorgensen, and J.S. Christiansen. 1989. Beneficial effects of growth hormone treatment in GH-deficient adults. Lancet. 1:1221-1225.

4. Salomon, F., R.C. Cuneo, R. Hesp, and P.H. Sonksen. 1989. The effects of treatment with recombinant human growth hormone on body composition and metabolism in adults with growth hormone deficiency. N. Engl. J. Med.321: 1797-1803.

5. Moller, N., J.O.L. Jorgensen, K.G. Alberti, A. Flyvbjerg, and O. Schmitz. 1990. Short-term effects of growth hormone on fuel oxidation and regional substrate metabolism in normal man. J. Clin. Endocrinol. Metab. 70:1179-1186.

6. O'Sullivan, A.J., J.J. Kelly, D.M. Hoffman, J. Freund, and K.K.Y. Ho. 1994. Body composition and energy expenditure in acromegaly. J. Clin. Endocrinol. Metab. 78:381-386.

7. Hoffman, D.M., A.J. O'Sullivan, J. Freund, and K.K.Y. Ho. 1995. Adults with growth hormone deficiency have abnormal body composition but normal energy metabolism. J. Clin. Endocrinol. Metab. 80:72-77.

8. Mannor, D.A., L.M. Winer, M.A. Shaw, and G. Baumann. 1991. Plasma growth hormone binding $(\mathrm{GH})$ proteins: effects on $\mathrm{GH}$ binding to receptors and on GH action. J. Clin. Endocrinol. Metab. 73:30-34.

9. Lim, L., S.A. Spencer, P. McKay, and M.J. Waters. 1990. Regulation of growth hormone $(\mathrm{GH})$ bioactivity by a recombinant human GH-binding protein. Endocrinology. 127:1287-1291.

10. Powers, M.S., L. Schenkel, P.E. Darley, W.R. Good, J.C. Balestra, and V.A. Place. 1985. Pharmacokinetics and pharmacodynamics of transdermal dosage forms of $17 \beta$-estradiol: comparison with conventional oral estrogens used for hormone replacement. Am. J. Obstet. Gynecol. 152:1099-1106.

11. Chetkowski, R.J., D.R. Meldrum, K.A. Steingold, D. Randle, J.K. Lu, P. Eggena, J.M. Hershman, N.K. Alkjaersig, A.P. Fletcher, and H.L. Judd. 1986. Biological effects of transdermal estradiol. N. Engl. J. Med.314:1615-1620.

12. O'Sullivan, A.J., and K.K.Y. Ho. 1995. A comparison of the effects of oral and transdermal estrogen replacement therapy on insulin sensitivity in postmenopausal women. J. Clin. Endocrinol. Metab. 80:1783-1788.

13. O'Sullivan, A.J., J.J. Kelly, D.M. Hoffman, R.C. Baxter, and K.K.Y. Ho. 1995. Energy metabolism and substrate oxidation in acromegaly. J. Clin. Endocrinol. Metab. 80:486-491.

14. Ferrannini, E. 1988. The theoretical bases of indirect calorimetry: a review. Metabolism. 37:287-301.

15. Ho, K.Y., A.J. Weissberger, P. Marbach, and L. Lazarus. 1990. Therapeutic efficacy of the somatostatin analog 201-995 (octreotide) in acromegaly: effects of dose and frequency and long-term safety. Ann. Intern. Med. 112:173-181.

16. Baxter, R.C., A.S. Brown, and J.R. Turtle. 1982. Radioimmunoassay for somatomedin C: comparison with radioreceptor assay in patients with growthhormone disorders, hypothyroidism, and renal failure. Clin. Chem. 28:488-495.

17. Grizzle, J.E. 1965. The two-period change-over design and its use in clinical trials. Biometrics. 21:467-480.

18. Writing group for the PEPI trial. 1995. Effects of estrogen or estrogen/ progestin regimens on heart disease risk factors in postmenopausal women. JAMA (J. Am. Med. Assoc.). 273:199-208.

19. Goldzieher, J.W., L.E. Moses, E. Averkin, C. Scheel, and B.Z. Taber. 1971. A placebo-controlled double-blind crossover investigation of the side effects attributed to oral contraceptives. Fertil. Steril. 22:609-623.

20. Pratt, W.F., and C.A. Bachrach. 1989. What do women use when they stop using the pill? Fam. Plann. Perspect. 19:257-266.

21. Riddoch, G.G., P. Duncombe, and G.T. Kovacs. 1966. Tasmanian survey of pill symptoms. Aus. Fam. Phys. 25:S38-S40.

22. Suter, P.M., Y. Schutz, and E. Jequier. 1992. The effect of ethanol on fat storage in healthy subjects. N. Engl. J. Med. 326:983-987.

23. Zurlo, F., S. Lillioja, P. Esposito-Del, B.L. Nyomba, I. Raz, M.F. Saad, B.A. Swinborn, W.C. Knowler, C. Bogardus, and E. Ravussin. 1990. Low ratio of fat to carbohydrate oxidation as predictor of weight gain: study of 24-h RQ. Am. J. Physiol. 259:E650-E657.

24. Walker, J.L., M. Ginalska-Malinowska, T.E. Romer, J.B. Pucilowska, and L.E. Underwood. 1991. Effects of the infusion of insulin-like growth factor 1 in a child with growth hormone insensitivity syndrome (Laron Dwarfism). $N$. Engl. J. Med. 324:1483-1488.

25. Mauras, N., and B. Beaufrere. 1995. Recombinant human insulin-like growth factor-I enhances whole body protein anabolism and significantly diminishes the protein catabolic effects of prednisone in humans without a diabetegenic effect. J. Clin. Endocrinol. Metab. 80:869-874.

26. Hussain, M.A., O. Schmitz, A. Mengel, Y. Glatz, J.S. Christiansen, J. Zapf, and E.R. Froesch. 1994. Comparison of the effects of growth hormone and insulin-like growth factor I on substrate oxidation and on insulin sensitivity in growth hormone-deficient humans. J. Clin. Invest. 94:1126-1133.

27. O'Sullivan, A.J., D.H. Hoffman, and K.K.Y. Ho. 1995. Estrogen, lipid oxidation and body fat. N. Engl. J. Med. 333:669-670

28. Moller, J., J.O.L. Jorgensen, N. Moller, J.S. Christiansen, and J. Weeke. 1992. Effects of growth hormone administration on fuel oxidation and thyroid function in normal man. Metabolism. 7:728-731.

29. Weinstein, I., C. Soler-Argilaga, H.V. Werner, and M. Heimberg. 1979. Effects of ethynyloestradiol on the metabolism of $\left[1-{ }^{14} \mathrm{C}\right]$ oleate by perfused livers and hepatocytes from female rats. Biochem. J. 180:265-271.

30. Ockner, R.K., N. Lysenko, J.A. Manning, S.E. Monroe, and D.A. Burnett. 1980. Sex steroid modulation of fatty acid utilization and fatty acid binding protein concentration in rat liver. J. Clin. Invest. 65:1013-1023.

31. Walsh, B.W., I. Schiff, B. Rosner, L. Greenberg, V. Ravnikar, and F.M. Sacks. 1991. Effects of postmenopausal estrogen replacement on the concentrations and metabolism of plasma lipoproteins. N. Engl. J. Med. 325:1196-1204.

32. Forbes, G.B. 1987. Human body composition. In Growth, Aging, Nutrition, and Activity. Springer-Verlag, New York. 169-195.

33. Rudman, D. 1985. Growth hormone, body composition and aging. $J$. Am. Geriatr. Soc. 33:800-807.

34. Forbes, G.B., and J.C. Reina. 1970. Adult lean body mass declines with age:some longitudinal observations. Metabolism. 19:653-663.

35. Novak, J.P. 1972. Aging, total body potassium, fat-free mass and cell mass in males and females between 18 and 85 years. J. Gerontol. 27:653-663.

36. Gutthann, S.P., L.A.G. Rodriguez, J. Castellsague, and A.D. Oliart. 1997. Hormone replacement therapy and risk of venous thromboembolism: population based case-control study. BMJ. 314:796-800.

37. Stampfer, M.J., G.A. Colditz, W.C. Willett, J.E. Manson, B. Rosner, F.E. Speizer, and C.H. Hennekens. 1991. Postmenopausal estrogen therapy and cardiovascular disease. N. Engl. J. Med. 325:756-762.

38. Nabulsi, A.A., A.R. Folsom, A. White, W. Patsch, G. Heiss, K.K. Wu, and M. Szklo. 1993. Association of hormone-replacement therapy with various cardiovascular risk factors in postmenopausal women. N. Engl. J. Med. 328: 1069-1075.

39. Barrett-Connor, E., D.L. Wingard, and M.H. Criqui. 1989. Postmenopausal estrogen use and heart disease risk factors in the 1980s. JAMA (J. Am. Med. Assoc.). 261:2095-2100.

40. Manolio, T.A., C.D. Furberg, L. Shemanski, B.M. Psaty, D.H. O'Leary, R.P. Tracy, and T.L. Bush. 1993. Associations of postmenopausal estrogen use with cardiovascular disease and its risk factors in older women. Circulation. 88: 2163-2171.

41. Goldman, L., and A.N.A. Tosteson. 1991. Uncertainty about postmenopausal estrogen. N. Engl. J. Med. 325:800-802.

42. Barrett-Connor, E. 1991. Postmenopausal estrogen and prevention bias. Ann. Intern. Med. 115:455-456.

43. Petitti, D.B., J.A. Perlman, and S. Sidney. 1986. Postmenopausal estrogen use and heart disease. N. Engl. J. Med.315:131-132.

44. Posthuma, W.F.M., R.G.J. Wstendorp, and J.P. Vandenbroucke. 1994. Cardioprotective effect of hormone replacement therapy in postmenopausal women: is the evidence biased. BMJ. 308:1268-1269. 